\title{
Gaming frequency and academic performance
}

\author{
Barry Ip \\ Swansea Metropolitan University, UK \\ Gabriel Jacobs \\ University of Tennessee, USA \\ Alan Watkins \\ Swansea University, UK
}

\begin{abstract}
There are numerous claims that playing computer and video games may be educationally beneficial, but there has been little formal investigation into whether or not the frequency of exposure to such games actually affects academic performance. This paper explores the issue by analysing the relationships between gaming frequency - measured as the amount of time undergraduate students spend playing games in their free time - and their academic performance as measured by their examination marks. Using a sample of 713 students, correlation analyses between gaming frequency and examination performance were conducted for students of varying gaming frequency, study discipline, gender, and general attitudes towards gaming and study. The results reveal that examination marks are in fact negatively correlated with gaming frequency - i.e. frequent gamers generally achieve lower marks than less frequent gamers.
\end{abstract}

\section{Introduction}

The aim of this paper is to investigate a comparatively untouched area of research into games and education: whether or not there is a link between the frequency with which computer and video games are played, and academic achievement, as measured by traditional examination results, of those who play them.

Gaming frequency is defined here not in terms of implementation within any controlled or educational environment such as those described in intervention studies, but rather in terms of the pastime which commercial developers generally intend their games to be. The hypothesis is that there may be statistically significant variations between gaming frequency and performance in examinations for certain academic subjects - for instance, whether frequent gamers perform better in technical subjects; or whether those who prefer games of certain genres, such as collaborative role-playing games, perform better in, say, humanities subjects. It is important to note at the outset that if such relationships do exist, it would be difficult if not impossible to determine any causal factors. It may be that students who perform well in certain subjects are already attracted to video games, perhaps more easily becoming addicted to them than those who perform less well. Only controlled experiments could uncover the possible fact that frequent game playing improves performance, or the reverse, and it would be a formidable feat to design an experiment which would give foolproof results since so many variables, known and unknown, are likely to have an effect. This paper, then, is concerned not with attempting to determine the effect of a pre-defined course of game 
playing on academic performance in examinations, but, more simply, with exploring whether or not there exist any links between the two. Nevertheless, as will be seen, the results of a questionnaire provide an interesting insight into some commonly held beliefs, such as that time spent playing video games is time wasted as far as academic achievement is concerned, or - surprisingly, not an uncommon idea - that the reverse is true, that is, that game playing trains the mind.

The following is a brief overview of prominent issues relating to computer and video games in education, provided here as background to the results to be presented in this paper.

\section{The effect of computer and video games}

Since their introduction as mass market products in the 1970s, computer and video games have come under scrutiny in a number of contentious areas. Fuelled by the ever increasing popularity and economic significance of the games industry (Dixon \& Karboulonis, 2000; Aoyama \& Izushi, 2003; Schilling, 2003), any negative findings such as those relating to gaming addiction (Fisher, 1994), epilepsy (Badinand-Hubert et al, 1998), aggression (Bensley \& Van Eenwyk, 2001), and violent content (Kirsh, 2003; Anderson, 2004) have rapidly been picked up by the media, often leading to condemnations of such games by the public. A prime example in the UK was that of the game Manhunt. The parents of a murdered teenager claimed that by depicting methods for committing murderous acts, the game represented a significant influential factor in triggering their son's killing by a 17-year-old boy who was reported to have been obsessed by the game (BBC, 2004a, 2004b). While the claims were eventually rejected by those investigating the case, these and similar incidents have certainly contributed towards the view, held by many, that video games are harmful to health and mental stability.

On the other hand, there has recently been a growing amount of research into the possible benefits of game playing, such as that of promoting ICT skills, and of its being an added motivational component for sports training, and even formal education (Fery \& Ponserre, 2001; Huggins \& Izushi, 2002; Rosas et al, 2003). Sophisticated computer simulations have been used for many years as training tools for real life applications such as driving, flight, and combat, the effectiveness of which can hardly be doubted (see, for example, Provenzo, 1991; pp.132-5; Herz, 1997; pp.197-213; Prensky, 2001; pp.295-316; EDGE (114), 2002; pp.62-8; Macedonia, 2002). Similarly, modern commercial electronic games running on the latest PCs and dedicated consoles are highly complex software applications. The latest multi-million selling titles such as Grand Theft Auto, The Sims, and The Legend of Zelda can deliver realistic content. Interaction with such games, especially in the ability to progress successfully within them, requires gamers to possess, or acquire, not only spatial skills, fast reaction times, and knowledge of intricate controls, but also skills for solving problems.

Consequent on this, Prensky (2001; pp.13-9) has offered an extensive debate on the growing potential (proven or otherwise) of the use of formal interactive applications and commercial games in educational contexts. It is posited that one of the major advantages intrinsic to commercial games is that they are fun, and that they therefore engage those who play them - benefits which are often absent from formal training and/or learning applications (Prensky, 2001; pp.17-9; pp.108-9; pp.149-51). Hence, a chief recommendation is that of adapting the strengths of commercial games to the 
requirements of education in order to motivate, stimulate and thus maximise the likelihood of a successful learning experience.

An extensive summary of the literature pertaining to computer games and education can be found in Mitchell \& Savill-Smith (2004), and an overview of the contexts in which games have been used in teaching can be found in Prensky (2001), Jayakanthan (2002) and Jackson (2004), who between them address commercial games as well as those developed especially for educational purposes (so-called edutainment), and who stress the potency and general potential of games as instructional tools. Other research provides evidence that games are advantageous for various aspects of cognitive development, including spatial awareness (Greenfield et al, 1994; Beck et al, 2003), enhanced attention and motivation (Blumberg, 1998; Rosas et al, 2003), experiential learning (Feinstein et al, 2002), promoting deeper thinking (Hong \& Liu, 2003), and problem solving (Perrone et al, 1996). Thus, despite concerns surrounding various technical obstacles and implementation issues, the time consuming and complex nature of modern electronic games for use in classroom environments, and the possible absence of a clear educational purpose (Becta, 2001; p.13; McFarlane et al, 2002; Egenfeldt-Nielsen, 2004), it is not all that surprising that commercial games have been fairly extensively reported as being powerful tools for enhancing ICT skills, as engaging users with the educational content in a way hard to achieve by other means, as encouraging collaborative working, and as increasing self esteem and library use (Becta, 2001; p.13; Mitchell \& Savill-Smith, 2004).

Gee (2003) identifies 36 areas of learning embedded in well designed video games which, it is argued, contribute towards promoting a much richer form of cognitive development than traditional modes of teaching. Gee (2004; p.199) further stresses that while what is learned in games may not necessary be morally 'good' (acts of wanton violence, glorification of tragedies in human history), the learning process is more often than not a highly effective one. There are claims that specific cognitive skills can be developed when games with no specifically intended educational purpose are played outside the classroom (BBC, 2006). Indeed, Prensky (2001; p.156) has highlighted distinct types of learning which can, in theory, be taught via particular game genres beyond those intended as educational tools - aspects which will be tested to some degree in the study presented in this paper. However, it is worth highlighting at this point that the aim of the study has not been to argue for or against those issues, as many of the studies mentioned above have done, but has merely been aimed at determining the influence of unmonitored and unrestricted access to commercial games on examination performance - from which conclusions may or may not be validly drawn.

\section{Methods}

In order to derive a suitably representative sample of participants for this study, careful consideration of the sampling technique was required. It was decided that a survey of all undergraduate students at our own institution - Swansea University in the UK - would be a viable and realistic option to derive statistically significant results if they existed. A short, web based questionnaire was devised, containing seven questions for gamers, and five for non-gamers (see Appendix for the questionnaire). The questions were designed to assess the amount of time and resources respondents spent on games, together with their attitudes towards the medium and other forms of popular entertainment such as cinema, music, and television. Attitudinal responses 
were measured using Likert scales, and additional comments were encouraged throughout.

Due to potential issues of privacy surrounding the use of examination results for this research, from the outset advice was sought from the University's Data Privacy Officer. Two stipulations were made: 1) in order to comply with the UK Data Protection Act and University regulations, explicit permission needed to be obtained from participating students to allow the analysis of questionnaire results in conjunction with their individual examination marks (retrieved from the University's examinations database); and 2) students' personal details had to be kept strictly anonymous in any publication. The objectives of the research, along with the two stipulations, were clearly stated on the front page of the questionnaire. Students were obliged actively to place a tick in a box to confirm they agreed with these terms before they could proceed to the questionnaire.

A pilot survey was carried out with 20 undergraduate students. Once the procedures and questionnaire had been finalised, all undergraduate students at the University were sent a standard email containing the details described above and asking them to participate in the survey (details of the duration and timing of the survey are specified in the next section). The emails were sent using an electronic mailing list which contained the standard University email accounts for all undergraduate students (approximately 7,000 at the time of the project), allocated to them at the time of their enrolment at the University. An Internet link was included in the email directing students to the online questionnaire. All responses were automatically stored onto an Access database for subsequent analysis. In order to verify the legitimacy of responses, students were required to state their unique student identification number on the questionnaire. This also helped to protect against the possibility of bogus participants and duplicate questionnaires being completed by individual students.

\section{Results}

An encouraging 1,187 responses were obtained (a rate of 17\%), although several could not be used for the final analysis due to two main reasons: 1) incomplete answers to the questionnaire; and 2) inadmissible cases, where assessment results were unavailable (students on an intercalary year, postgraduate research, studies suspended, and so forth). Further, in order to derive valid comparisons of assessment results, two additional restrictions were placed on the validity of responses. Respondents had to be (a) registered on full degree schemes at Level 1, Level 2 or Level 3 (normally respectively representing first, second or third year of study); and (b) studying under the conventional University modular structure (i.e. to be studying for 120 credits in their year of study, thus being full time students). Strictly applying these criteria brought the final number of valid responses down to a still very usable 713 .

Students' academic performance was measured by taking their assessment results for all modules studied during the 2003 to 2004 academic year. The survey was administered in mid-June 2004, after the completion of all assessments, but prior to the summer vacation and for a total of 14 days from when the original invitation email was sent (see above). Using these assessment results, an overall examination mark for each student was then calculated as a percentage using the University's standard procedure. The majority of results are derived from traditional formal examinations, but due to the broad variety of subject areas incorporated into this analysis, students' 
overall marks may contain a small mixture of other assessment formats such as coursework and practical or laboratory tests. A detailed breakdown of results for individual study schemes is given below.

Where appropriate, statistical analyses were performed using SPSS. For the most part, statistical and correlational data will be presented here in tabulated form for concision, while analysis of attitudinal questions in the survey will be shown in graphical format for ease of comparison and interpretation. All data used in the analysis were tested for normality to determine the most appropriate tests of significance. Tests employed as the result of this procedure will be specified throughout the discussion. The use of tables and graphs will be combined in instances where the findings demonstrate a mixture of attitudinal and statistical significance.

\section{Demographic and student data}

There was a fairly well balanced male and female split: 369 to 344 respectively, with 354 students at Level 1, 210 at Level 2, and 149 at Level 3. As for student type, there were 292 undergraduates mainly studying humanities (non-numerical subjects), 327 studying Science pure and/or applied (largely numerical), and 94 studying a mixture of the two. The mean examination mark for all students was $56.1 \%$ (standard deviation of 11.4), a Kolmogorov-Smirnov test revealing that the marks were not normally distributed, and skewed towards the lower end of the range.

Students were placed into one of four gamer categories which determined the extent to which they played computer and/or video games. It can be seen in Table 1, which specifies the composition of each gamer group, that over $88 \%$ of students were gamers in some capacity, with over $71 \%$ being regular or frequent gamers (spending, on average, at least one hour per day playing games).

Table 1: Number of students in each gamer group

\begin{tabular}{|l|l|c|}
\hline \multicolumn{1}{|c|}{ Gamer group } & N \\
\hline Group 1 & $\begin{array}{l}\text { Non-gamers - do not spend any time playing games; do not own any } \\
\text { games or games machine; never buy games or games related } \\
\text { products. }\end{array}$ & 81 \\
\hline Group 2 & $\begin{array}{l}\text { Infrequent gamers - spend, on average, less than one hour per day } \\
\text { playing games but own at least one games machine or game; rarely } \\
\text { buy games or games-related products. }\end{array}$ & 121 \\
\hline Group 3 & $\begin{array}{l}\text { Regular gamers - spend, on average, between one and two hours per } \\
\text { day playing games; own games machines and games; occasionally } \\
\text { buy games or games-related products. }\end{array}$ & 433 \\
\hline Group 4 & $\begin{array}{l}\text { Frequent gamers - spend, on average, more than two hours per day } \\
\text { playing games; own games machines and games; regularly buy } \\
\text { games or games-related products. }\end{array}$ & 78 \\
\hline
\end{tabular}

The following results are divided into increasing levels of detail with respect to an assessment of relationships between gaming habit and academic performance. First, a broad analysis is presented, which concentrates on the three main disciplines mentioned above (Humanities, Science, and a mixture of the two). This is followed by a more detailed examination of specific degree schemes, such as Business Studies, Computer Science, Engineering, and Psychology. Finally, we present an analysis of other pertinent aspects of the study. 


\section{Analysis of gamers across broad subject areas}

Table 2 shows summary statistics for the three main disciplines - Humanities, Science, and mixed - with respect to gamer groups defined in Table 1. On the whole, frequent gamers (Group 4) achieved noticeably lower overall examination results across all three disciplines as compared to less frequent gamers from any of the other groups. In particular, comparing the results of Group 1 with Group 4 reveals that average examination results for non-gamers were a not insubstantial 7.3\%, 3.8\%, and 9.4\% higher than frequent gamers for Humanities, Science, and mixed subjects respectively.

Table 2: Summary statistics for three main disciplines with respect to gamer type

\begin{tabular}{|c|l|c|c|c|c|c|}
\hline $\begin{array}{c}\text { Gamer } \\
\text { group }\end{array}$ & \multicolumn{1}{|c|}{ Discipline } & $\mathrm{N}$ & $\begin{array}{c}\text { Mean examin- } \\
\text { ation result (\%) }\end{array}$ & Maximum & Minimum & S.D. \\
\hline \multirow{2}{*}{1} & Humanities/non-numerical & 40 & 57.8 & 76.7 & 36.7 & 10.1 \\
\cline { 2 - 7 } & Science/numerical & 29 & 57.7 & 74.8 & 24.1 & 11.8 \\
\cline { 2 - 7 } & Mixture & 12 & 61.9 & 74.7 & 45.8 & 6.8 \\
\cline { 2 - 7 } & Mean & & 58.4 & & & \\
\hline \multirow{2}{*}{2} & Humanities/non-numerical & 65 & 58.3 & 69.7 & 36.2 & 6.6 \\
\cline { 2 - 7 } & Science/numerical & 34 & 62.3 & 92.3 & 40.0 & 11.5 \\
\cline { 2 - 7 } & Mixture & 22 & 57.8 & 85.7 & 26.9 & 12.2 \\
\cline { 2 - 7 } & Mean & & 59.3 & & & \\
\hline \multirow{3}{*}{3} & Humanities/non-numerical & 166 & 56.3 & 80.8 & 13.5 & 10.0 \\
\cline { 2 - 7 } & Science/numerical & 212 & 54.6 & 84.9 & 7.7 & 13.3 \\
\cline { 2 - 7 } & Mixture & 55 & 55.5 & 71.2 & 17.4 & 9.4 \\
\cline { 2 - 7 } & Mean & & 55.4 & & 25.8 & 9.5 \\
\hline \multirow{2}{*}{4} & Humanities/non-numerical & 21 & 50.5 & 62.3 & 36.2 & 13.5 \\
\cline { 2 - 7 } & Science/numerical & 52 & 53.9 & 59.7 & 9.5 \\
\cline { 2 - 7 } & Mixture & 5 & 52.5 & & & \\
\cline { 2 - 7 } & Mean & & & & & \\
\hline
\end{tabular}

Table 3: Summary statistics for three main disciplines with respect to gender

\begin{tabular}{|c|c|c|c|c|c|c|}
\hline Gender & Discipline/Gamer group & $\mathrm{N}$ & $\begin{array}{l}\text { Mean examin- } \\
\text { ation result }(\%)\end{array}$ & Maximum & Minimum & S.D. \\
\hline \multirow[t]{7}{*}{ Male } & Humanities/non-numerical & 109 & 54.2 & 80.8 & 13.5 & 10.7 \\
\hline & Science/numerical & 223 & 54.7 & 88.2 & 7.7 & 13.8 \\
\hline & Mixture & 37 & 56.4 & 74.7 & 17.4 & 10.4 \\
\hline & Group 1 - non gamer & 14 & 57.5 & 74.7 & 36.7 & 11.1 \\
\hline & Group 2 - infrequent gamer & 25 & 60.1 & 85.8 & 35.7 & 11.3 \\
\hline & Group 3-regular gamer & 263 & 52.9 & 82.0 & 7.7 & 12.7 \\
\hline & Group 4 - frequent gamer & 67 & 54.5 & 88.2 & 25.8 & 12.8 \\
\hline \multirow[t]{7}{*}{ Female } & Humanities/non-numerical & 183 & 57.9 & 76.7 & 21.5 & 8.4 \\
\hline & Science/numerical & 104 & 57.6 & 92.3 & 24.1 & 11.5 \\
\hline & Mixture & 57 & 56.9 & 85.7 & 26.9 & 9.8 \\
\hline & Group 1 - non gamer & 67 & 58.6 & 76.7 & 24.1 & 10.3 \\
\hline & Group 2 - infrequent gamer & 96 & 59.1 & 92.3 & 26.9 & 8.9 \\
\hline & Group 3 - regular gamer & 170 & 56.8 & 84.9 & 21.5 & 9.6 \\
\hline & Group 4 - frequent gamer & 11 & 53.0 & 74.8 & 40.2 & 9.4 \\
\hline
\end{tabular}

Consistent with expectations, gender comparisons showed that female students performed better than male students across all three disciplines, while non- and infrequent male and female gamers also out-performed more frequent gamers - see Table 3 . In the case of male gamers, the largest mean difference was between Group 2 
and Group $3(7.2 \%)$ - i.e. examination marks of infrequent male gamers averaged $7.2 \%$ higher than those for regular male gamers. For females, Group 2 (infrequent gamers) averaged $6.1 \%$ higher than Group 4 (frequent gamers).

To explore this data in further detail, a Mann-Whitney $U$ test was conducted to see whether any significant differences exist between the marks of these gamers. A statistically significant difference was found between males and females at the $99 \%$ level. Numerous differences were also observed between gamer groups (see Table 4), whilst no significant differences were found between any of the three broad study disciplines.

Table 4: Man-Whitney U test results for examination marks between gamer types

\begin{tabular}{|l|c|c|c|c|}
\hline \multicolumn{1}{|c|}{ Variable } & $\begin{array}{c}\text { Group 1 } \\
\text { non gamer }\end{array}$ & $\begin{array}{c}\text { Group 2 } \\
\text { infrequent }\end{array}$ & $\begin{array}{c}\text { Group 3 } \\
\text { regular }\end{array}$ & $\begin{array}{c}\text { Group 4 } \\
\text { frequent }\end{array}$ \\
\hline Group 1 - non gamer & - & No difference & $0.02^{*}$ & $0.00^{* *}$ \\
\hline Group 2 - infrequent gamer & - & - & $0.00^{* *}$ & $0.00^{* *}$ \\
\hline Group 3 - regular gamer & - & - & - & $0.02^{*}$ \\
\hline Group 4 - frequent gamer & - & - & - & - \\
\hline
\end{tabular}

${ }^{*}$ A significant difference at the $95 \%$ level ${ }^{* *}$ A significant difference at the $99 \%$ level

Students in gamer Groups 3 and 4 were asked two additional questions:

1. Do you think that playing games gives you a better chance of improving your performance in assignments and/or exams?

2. Do you stop playing games during or approaching a busy time of study (e.g. lots of assignments, exam periods)?

Figure 1 reveals that a small percentage of regular and frequent gamers felt that playing games can improve or reduce academic performance, although the majority felt that doing so has no notable effect (over 60\% in both gamer groups). Even so, over $50 \%$ of regular gamers and $60 \%$ of frequent gamers said that they reduced the amount of time playing games during or when approaching busy study periods (Figure 2).

Whatever students' attitudes, there remains the question of whether or not any statistically significant relationships exist between examination results and gamer type. Using the appropriate tests depending on the normality of data within various gamer groups, a correlation analysis (Pearson correlation for normal data, and Spearman's correlation for non-normal) was performed to explore this matter. The results in Table 5 are startling, as it can be clearly seen that there is a statistically significant negative correlation between gamer type and examination results: frequent gamers achieve lower marks than non-gamers. This finding is true when examination results are taken as a whole (significant at the 99\% level), across the three main study disciplines (95\% level), and also between males and females (99\% and 95\% levels respectively).

As emphasised at the beginning of this paper, although causality cannot be determined, the significance of these results raises concerns as to why frequent gamers perform less well in examinations than non-gamers. In addition, having seen above that a large proportion of gamers reduce their gaming time during busy study periods (and assuming this attitude is actually true in practice), it would appear that any causes which may result from gaming asserts a longer term influence than would initially be expected; that is to say that increasing or reducing gaming time during a busy period makes little or no difference to examination results. 


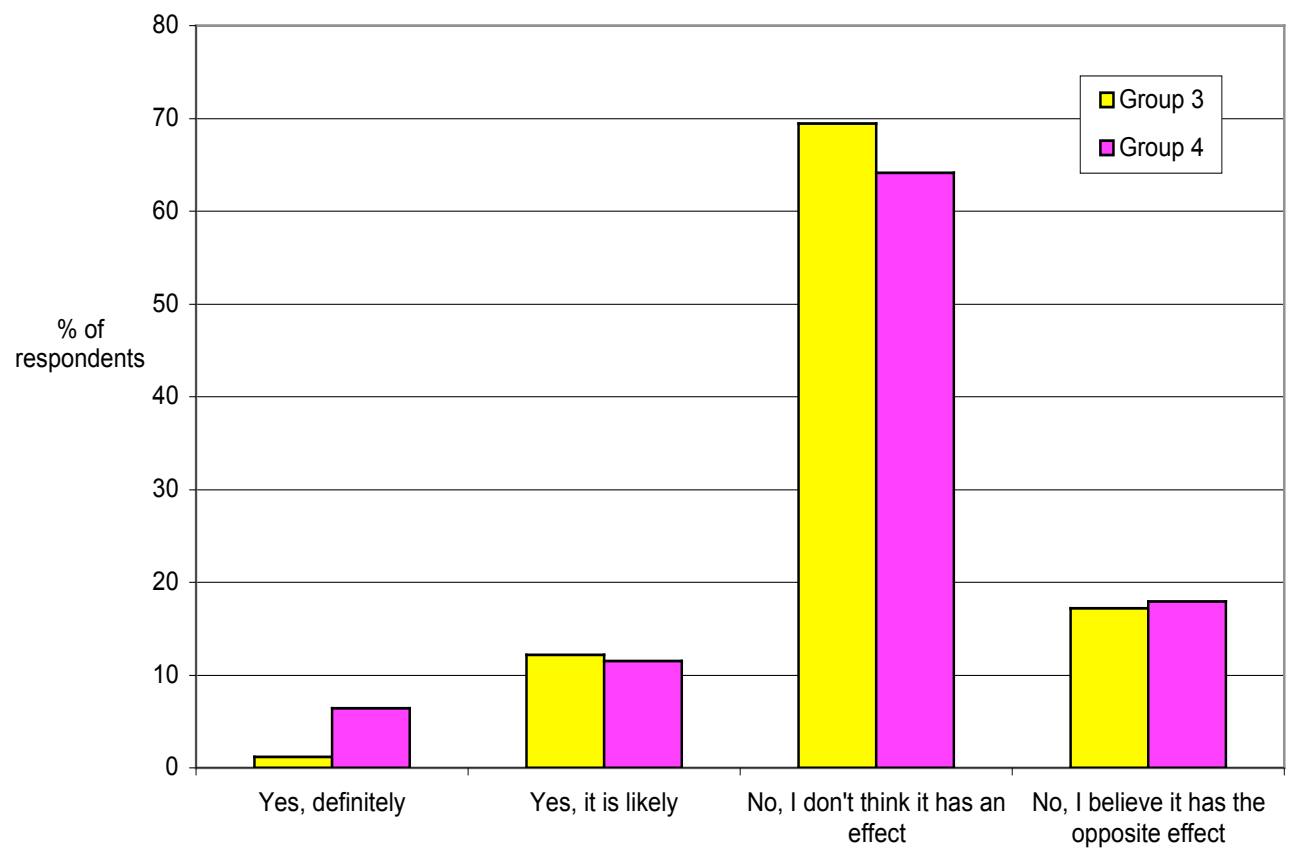

Figure 1: Do you think that playing games gives you a better chance of improving your performance in assignments and/or exams?

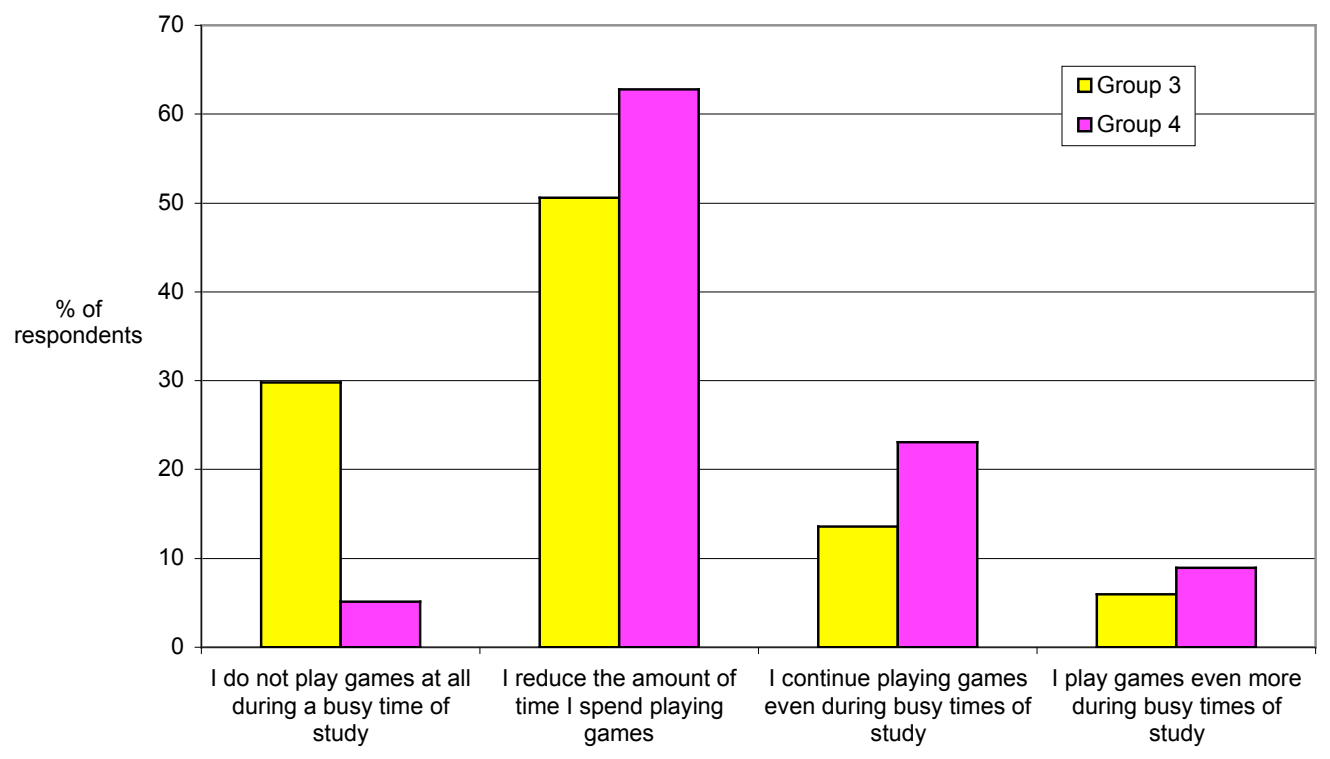

Figure 2: Do you stop playing games during or approaching a busy time of study (e.g. lots of assignments, exam periods)? 
Table 5: Correlations between examination results and gamer type

\begin{tabular}{|l|c|c|}
\hline \multicolumn{1}{|c|}{ Correlation variables } & $\mathrm{n}$ & $\begin{array}{c}\text { Correlation } \\
\text { coefficient }\end{array}$ \\
\hline Gamer group and all exam results & 713 & $-0.18^{* *}$ \\
\hline Gamer group and humanities exam results & 292 & $-0.14^{*}$ \\
\hline Gamer group and science exam results & 327 & $-0.13^{*}$ \\
\hline Gamer group and mixed-subject exam results & 94 & $-0.23^{*}$ \\
\hline Gamer group and male students' exam results & 369 & $-0.15^{* *}$ \\
\hline Gamer group and female students' exam results & 344 & $-0.11^{*}$ \\
\hline
\end{tabular}

* Significant at the $95 \%$ level ${ }^{* *}$ Significant at the $99 \%$ level

To explore this particular avenue further, we investigated whether any significant differences existed between examination results of gamers who reduce or do not play games during study periods $(\mathrm{n}=390)$, and those who continue or increase play time (n $=107$ ). A non-parametric Mann-Whitney $U$ test was conducted (since examination results for the 497 students belonging to these two groups were not normally distributed). The results in Table 6 show, interestingly, that no statistically significant difference exists between examination marks of these gamers, thus confirming the hypothesis that increasing or reducing gaming time during busy study periods (as, of course, claimed by the respondents) does not lead to significant differences.

Table 6: Mann-Whitney U test for attitudes towards game playing during study periods

\begin{tabular}{|l|c|}
\hline & Output \\
\hline Gamers who reduce or do not play games during study periods & $\mathrm{N}=390$ \\
\hline Gamers who continue or increase play time & $\mathrm{N}=107$ \\
\hline Mann-Whitney U & 18331.0 \\
\hline Wilcoxon W & 24609.0 \\
\hline Z & -1.546 \\
\hline Asymp. Sig. (2-tailed) & 0.122 \\
\hline
\end{tabular}

An analysis was also performed with the aim of exploring any relationships between gaming genres and examination results. Modern games offer a wide variety of content, differing in length, complexity, and context, all of which are generally dependent on the genre to which the game belongs. For example, action and racing games tend to require quick reactions, while strategic and role playing or cooperative games require considered tactics and planning. Due to the increasing complexities of these games, and the skill required to learn their intricacies, it is plausible that gamers who engage in a wide range of genres may be more adept in learning and applying such skills beyond the gaming environment.

In an attempt to determine whether or not these skills have any impact on academic performance, students were simply asked: What types of game do you own/play? They were given the choice of seven answers, and invited to tick as many as applied racing, action, sports, simulation, strategy/role playing, shooting, and other (specified by participants in the questionnaire). An initial inspection of the data revealed that over $80 \%$ of gamers owned or played at least two genres, with considerable overlap between gamers in the types of genre played, and hence an analysis of individual genres in this study would be neither practical nor statistically reliable. However, students were categorised into one of two groups - those who owned or regularly 
played three or fewer game genres $(n=516)$, and those who owned or played four or more genres $(n=197)$. A Mann-Whitney $U$ test (applied, consistent with the above, in view of non-normal data for this section of the analysis) showed a statistically significant difference between the two groups (see Table 7) - examination results differ between gamers who play three genres or fewer, and those who play four or more. A Spearman's correlation found a significant negative correlation (coefficient of -0.10) at the $99 \%$ level between examination results and number of genres played: gamers of four or more game genres generally perform less well in examinations.

Thus, yet again, it seems that despite the reported advantages of games in terms of their ability to stimulate enhanced learning and motivation (but also bearing in mind yet again that no claim for causality is advanced here), the evidence we collected supports a negative relationship between gaming experience (with respect to engagement in various genres) and academic performance. The possible implications of these results are discussed in the concluding part of the paper, the findings calling for a more detailed analysis, since one might have expected, for example, that frequent gamers would perform better in certain specific subject areas, such as computing.

Table 7: Mann-Whitney $U$ test for the number of genres played by students

\begin{tabular}{|l|c|}
\hline & Output \\
\hline Gamers who owned or regularly played three or fewer game genres & $\mathrm{N}=516$ \\
\hline Gamers who owned or played four or more genres & $\mathrm{N}=197$ \\
\hline Mann-Whitney U & 44471.5 \\
\hline Wilcoxon W & 63974.5 \\
\hline Z & -2.584 \\
\hline Asymp. Sig. (2-tailed) & 0.010 \\
\hline
\end{tabular}

\section{Further analyses}

In order to keep the data manageable for this further analysis, academic disciplines were grouped into one of six main categories broadly based on the cognate nature of the subject areas. Table 8 shows the disciplines and the number of students in each category. As above, a Spearman's correlation test was performed to determine whether or not any statistically significant relationships existed between subject-areas and gamer type. As can be seen, the results in Table 8 indicate that, despite some negative correlations, there were no significant relationships between gamer type and examination performance in subject categories 1, 2, 3, and 4. However, statistically significant negative correlations (at the $95 \%$ level) were found between gamer type and subject categories 5 and 6 - that is, frequent gamers perform less well in biological and physical science subjects, and language studies.

Despite the evidence to support a link between gaming frequency and general academic performance, it is plausible that indulging in other similar social activities may also have a bearing on examination results: spending time on any social activity, games or otherwise, might lead to similar effects. To gauge the validity of this hypothesis, students were asked: Apart from games, what is your attitude towards other forms of entertainment during busy periods of study? Here, students were presented with four categories: TV, music, cinema, and social activities (such as pubs, clubs, and parties). As with the questions above, students had to specify the frequency in which they engaged in these activities during heavy study periods on a Likert scale from 1 (not at all) to 4 (spend increased amount of time). 
Table 8: Subject categories and correlations between examination results within subject groups and gamer type

\begin{tabular}{|c|l|c|c|}
\hline \multicolumn{1}{|c|}{ Subject category } & $\mathrm{n}$ & $\begin{array}{c}\text { Correlation coefficient } \\
\text { (with gamer type) }\end{array}$ \\
\hline 1 & Business, Economics, Law & 130 & -0.14 \\
\hline 2 & $\begin{array}{l}\text { History, Cultural Studies, Philosophy, Politics, } \\
\text { International Relations }\end{array}$ & 130 & -0.14 \\
\hline 3 & Mathematics, Physics, Engineering, Computing & 156 & -0.14 \\
\hline 4 & Media Studies, Social Studies, Psychology, Anthropology & 79 & -0.11 \\
\hline 5 & $\begin{array}{l}\text { Biology, Chemistry, Zoology, Medical Studies, Geography, } \\
\text { Sports Science }\end{array}$ & 121 & $-0.23^{*}$ \\
\hline 6 & Language Studies, e.g. English, French, German & 97 & $-0.21^{*}$ \\
\hline
\end{tabular}

* Significant at the $95 \%$ level

Figure 3 shows that a large percentage of students reduce or eliminate the time spent on TV, cinema, and social events. Music is the only exception, where students tend to prefer to maintain or increase the amount of time spent on or with it.

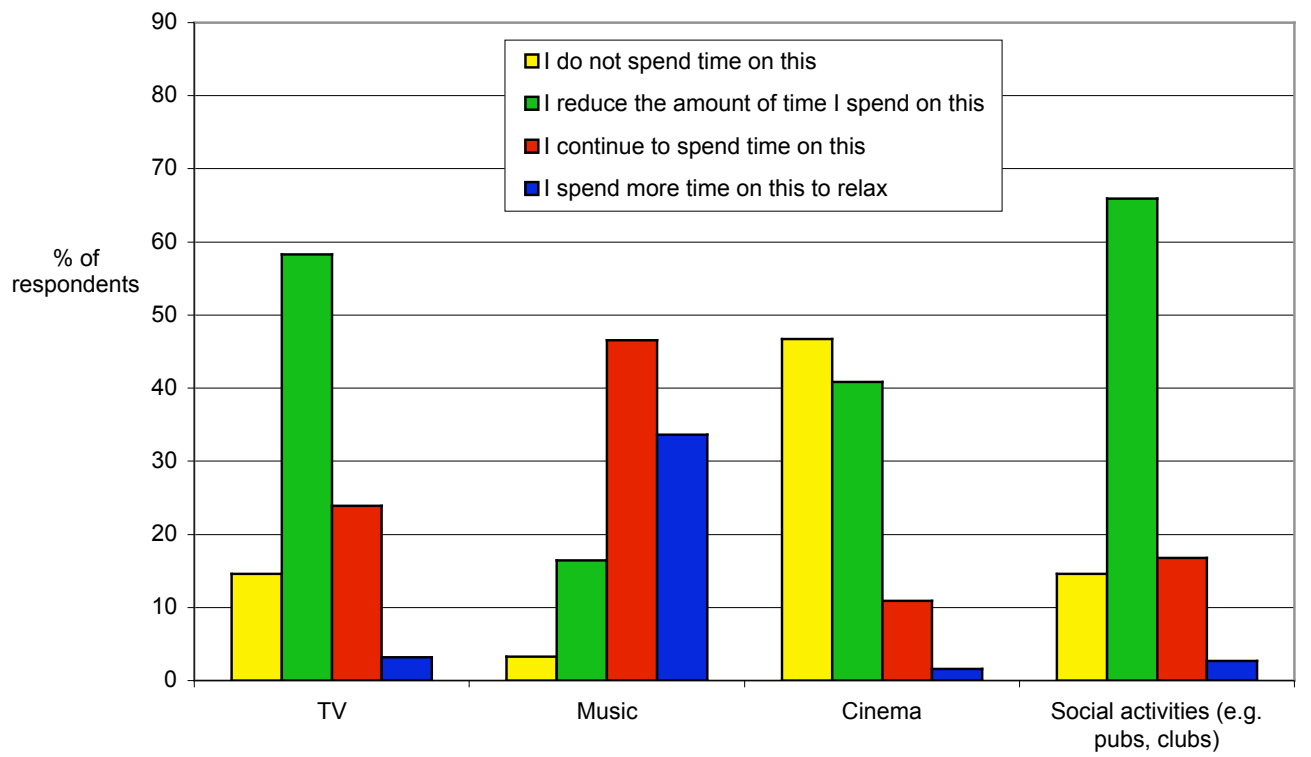

Figure 3: Apart from games, what is your attitude towards other forms of entertainment during busy periods of study?

However, a more detailed correlation analysis (as above, Spearman's technique was applied for non-parametric data - see Table 9) revealed no statistically significant relationships between the time spent on TV or cinema and examination results (unlike the consistent negative correlations associated with gaming frequency discussed above). Conversely, significant negative relationships were found between the time spent on music or social activities and examination results: students who maintained or increased the amount of time spent on these activities performed less well in examinations. This result is particularly interesting since, as can be seen in Figure 3, students' time spent on social activities is similar to that for TV, yet the correlations show that there is a significant academic implication associated with spending time on 
social activities during busy study periods. Somewhat unexpected was that the time spent listening to music was also linked (negatively) to examination performance, especially as numerous students highlighted it as an important medium for reducing stress, hence choosing to increase exposure to it during hectic periods.

Table 9: Spearman's correlations between examination results and entertainment activities

\begin{tabular}{|l|c|c|}
\hline \multicolumn{1}{|c|}{ Correlation variables } & $\mathrm{n}$ & $\begin{array}{c}\text { Correlation } \\
\text { coefficient }\end{array}$ \\
\hline Examination results and time spent on TV & 713 & -0.05 \\
\hline Examination results and time spent on music & 713 & $-0.09^{*}$ \\
\hline Examination results and time spent on cinema & 713 & -0.02 \\
\hline Examination results and time spent on social events & 713 & $-0.13^{* *}$ \\
\hline
\end{tabular}

For the final part of the analysis, an investigation was attempted to determine if any significant relationships existed between examination results, entertainment activities, and gaming frequency. The issue to be explored here was, then, whether or not gaming frequency, when combined with engagement in other forms of entertainment, could lead to reduced academic performance. Once more, the data were split into the appropriate gamer groups, and correlations between the relevant variables were assessed. As can be seen in Table 10, only two statistically significant relationships were found. At the 99\% level, for infrequent gamers (those spending less than one hour per day playing games), a negative relationship was found between TV viewing frequency and academic performance: infrequent gamers who are regular TV viewers during busy study periods generally achieve lower examination marks. The same result can also be observed for regular gamers (those who spent, on average, between one and two hours per day playing games), but who combined playing games with social events such as pubs and clubs. Remarkably, no significant relationships were found between exposure to entertainment and non- or frequent gamers. These results are discussed in the next section.

Table 10: Correlations between examination results and entertainment activities for various gamers

\begin{tabular}{|c|c|c|c|}
\hline \multicolumn{2}{|c|}{$\begin{array}{l}\text { Correlation variables for examination } \\
\text { results and time spent on }\end{array}$} & $\mathrm{n}$ & $\begin{array}{l}\text { Correlation } \\
\text { coefficient }\end{array}$ \\
\hline \multirow{4}{*}{$\begin{array}{l}\text { Group 1- non- } \\
\text { gamers }\end{array}$} & TV & 81 & -0.06 \\
\hline & music & 81 & -0.15 \\
\hline & cinema & 81 & -0.00 \\
\hline & social events & 81 & -0.11 \\
\hline \multirow{4}{*}{$\begin{array}{l}\text { Group } 2 \text { - } \\
\text { infrequent gamers }\end{array}$} & TV & 121 & $-0.25^{*}$ \\
\hline & music & 121 & -0.11 \\
\hline & cinema & 121 & -0.03 \\
\hline & social events & 121 & -0.14 \\
\hline \multirow{4}{*}{$\begin{array}{l}\text { Group } 3 \text { - regular } \\
\text { gamers }\end{array}$} & TV & 433 & -0.02 \\
\hline & music & 433 & -0.05 \\
\hline & cinema & 433 & -0.00 \\
\hline & social events & 433 & $-0.14^{*}$ \\
\hline \multirow{4}{*}{$\begin{array}{l}\text { Group } 4 \text { - frequent } \\
\text { gamers }\end{array}$} & TV & 78 & 0.05 \\
\hline & music & 78 & 0.04 \\
\hline & cinema & 78 & -0.03 \\
\hline & social events & 78 & -0.04 \\
\hline
\end{tabular}

* Significant at the $99 \%$ level 


\section{Discussion and conclusions}

The results derived from the research presented here raise several important issues concerning undergraduate students' use of computer and video games in relation to their academic performance. The most notable finding is the fact that there is a telling relationship between gaming and examination results, where, in most cases, frequent gamers perform less well than non- or infrequent gamers.

Within the general findings, the key messages are:

1. frequent gamers (measured as those who spend, on average, more than two hours per day playing games) are less likely to obtain higher marks across all subject disciplines than non- or infrequent gamers (result significant at the $99 \%$ level);

2. frequent gamers are less likely to obtain higher marks than non- or infrequent gamers in humanities/non-numerical, science/numerical, and mixed subject areas (result significant at $95 \%$ and $99 \%$ levels);

3. frequent male and female gamers are less likely to obtain higher marks than their non- or infrequent gaming counterparts (significant at 99\% and 95\% levels respectively);

4. as would be expected, students generally reduce gaming time during busy study periods, but no significant differences were found between examination marks of students who reduce gaming time and those who do not;

5. examination marks of gamers of four or more genres differ significantly from players of three game genres or fewer, with the former being less likely to get higher marks than the latter;

6. frequent gamers are less likely to achieve higher examination marks than non- or infrequent gamers in biological/physical sciences and language subjects, but no significant correlations were found in other mainstream subject areas (such as Business, Economics, History, Philosophy, Maths, Physics, Engineering, and Social Studies);

7. frequent gamers generally achieve lower marks than infrequent or non-gamers, but students who spend time on social events and listening to music also obtain lower examination marks. In addition, lower examination marks are correlated with combining infrequent gaming with regular TV viewing, and regular gaming with regular engagement in social events such as pubs and clubs.

Perhaps the most remarkable result of all is that not a single significant positive correlation was found between gaming frequency and academic performance - a finding which, in effect, vindicates the stereotypical view that gaming is detrimental (or at least of no benefit) to academic study. The patterns uncovered here show strong indications that frequent gamers (both males and females) generally perform less well than less frequent gamers in examinations. In some cases, examination marks of nongamers averaged up to $9.4 \%$ higher than frequent gamers. As a corollary, Tables 11 and 12 provide additional summaries of average marks, split according to two basic categories: year of study and gamer type. Again, the results draw attention to the stark contrast between non-gamers and frequent gamers. Take, for example, examination marks of second-year male students, where infrequent gamers averaged $11.1 \%$ higher 
than frequent gamers (Table 11); or second-year female students, where non-gamers averaged $10.1 \%$ higher than frequent gamers (Table 12).

Table 11: Summary of year of study and gamer type for male students

\begin{tabular}{|c|c|c|c|}
\hline $\begin{array}{c}\text { Year of } \\
\text { study }\end{array}$ & $\begin{array}{c}\text { Gamer } \\
\text { type }\end{array}$ & $\mathrm{n}$ & $\begin{array}{c}\text { Mean examin- } \\
\text { ation result (\%) }\end{array}$ \\
\hline 1 & 1 & 9 & 56.2 \\
& 2 & 11 & 56.1 \\
& 3 & 145 & 51.7 \\
& 4 & 33 & 51.3 \\
\hline 2 & 1 & 3 & 58.8 \\
& 2 & 10 & 65.1 \\
& 3 & 65 & 55.2 \\
& 4 & 21 & 54.0 \\
\hline 3 & 1 & 2 & 61.2 \\
& 2 & 4 & 58.7 \\
& 3 & 53 & 61.3 \\
& 4 & 13 & 55.2 \\
\hline
\end{tabular}

Table 12: Summary of year of study and gamer type for female students

\begin{tabular}{|c|c|c|c|}
\hline $\begin{array}{c}\text { Year of } \\
\text { study }\end{array}$ & $\begin{array}{c}\text { Gamer } \\
\text { type }\end{array}$ & $\mathrm{n}$ & $\begin{array}{c}\text { Mean examin- } \\
\text { ation result }(\%)\end{array}$ \\
\hline \multirow{4}{*}{1} & 1 & 32 & 56.1 \\
\cline { 2 - 4 } & 2 & 36 & 56.8 \\
\cline { 2 - 4 } & 3 & 85 & 55.4 \\
\cline { 2 - 4 } & 4 & 3 & 57.1 \\
\hline \multirow{4}{*}{2} & 1 & 17 & 61.1 \\
\cline { 2 - 4 } & 2 & 34 & 59.1 \\
\cline { 2 - 4 } & 3 & 53 & 57.7 \\
\cline { 2 - 4 } & 4 & 7 & 51.0 \\
\hline 3 & 1 & 18 & 60.6 \\
\cline { 2 - 4 } & 2 & 26 & 62.4 \\
\cline { 2 - 4 } & 3 & 32 & 58.8 \\
\cline { 2 - 4 } & 4 & 1 & 55.3 \\
\hline
\end{tabular}

It cannot, of course be stressed enough that while frequent gamers generally appear to obtain lower marks than non-gamers, there remains no proof that gaming causes any reduction in academic performance. Indeed, one could justifiably say that on the strength of this study, gaming should be considered no more damaging to examination performance than spending excessive time on TV, music, social events, or any other pastime. Further possible confounding variables include other extra-curricular activities such as part time employment, and mature students with family commitments - factors which would be worthwhile inclusions in similar future studies. With these issues in mind, the results should, therefore, be treated with a degree of caution. In order to substantiate these findings, further in depth, controlled experiments might offer more conclusive data to uncover specific factors which may cause a reduction in examination performance.

In addition, qualitative investigations into students' attitudes towards gaming will certainly help to facilitate a stronger verification of the relationships between gaming and academic performance. Additional follow up techniques such as in depth interviews and/or focus groups would be particularly appropriate for regular and frequent gamers where trends of relatively poor examination performance exist. 
Future studies of this type would also benefit from a more detailed breakdown of the composition of assessment methods (traditional examination, coursework, lab tests, and so on) to help identify any additional trends in academic performance. Unfortunately, due to the sheer quantity of degree courses and number of respondents involved in this study, this level of detail was not achievable in the available timeframe.

The evidence nonetheless supports the notion that there are significant links between gaming frequency and academic performance. Connected to this is the finding that no significant difference in examination performance can be observed from altering gaming time during busy study periods (arguably when any negative influence exerted via gaming would be most prominent), thus giving some indication that gaming has little or no influence over the short term. The obvious allure of interactive games as a key distraction during study periods calls for further research to explore the potential relationships between gaming frequency, academic performance, and student motivation. Such research could examine the possibility that students who perform less well in examinations (the frequent gamers) are not as motivated or as interested in their studies as students who perform better (the non- or infrequent gamers).

Although great care must be exercised in research of this type (since high motivation does not necessarily translate into high academic performance: Stipek, 1993; p.12), it is possible that, in particular, students who are intrinsically motivated (see Stipek, 1993; p.59; Lamb, 2001; Lieberman \& Remedios, 2007) - i.e. those inclined to learn for their own sake, without any reward - are more likely to be engaged in their studies (Pintrich et al, 1994; p.124, p.223), and generally develop a greater level of understanding of course material than less motivated students (Schiefele, 1991). Closely attached to this is the concept of motivational interference, where there is some evidence to indicate that students' motivation to learn (although primarily among adolescents) is reduced when a distraction is presented, such as watching television, browsing the Internet (Flowers \& O'Neill, 2005; Fries \& Dietz, 2007), or in this case, gaming. Hence, despite the link between gaming frequency and academic performance, this relationship may be the consequence of a lack of learning motivation rather than one of habitual gaming.

Finally, it should be said that it is important for parents and gamers not to automatically assume from the results presented in this paper that access to commercial, non-educational games has a direct effect (positive or negative) on academic performance, even if some learning or social advantages have been found in the context of educational games. A study by Huang \& Russell (2006) puts forward some evidence to suggest that while increased access to computers and the Internet helps to boost academic performance among school children, the idea that simply having access to new technologies will routinely enhance learning and achievement is surely a misconception. Consequently, the real challenge for the use of games as an educational tool is to strike a clear balance between encouraging controlled access to specifically designed games educational software, and frequent or uncontrolled exposure to commercial games in the home.

\section{References}

Anderson, C. (2004). An update on the effects of playing violent video games. Journal of Adolescence, 27(1), 113-122. 
Aoyama, Y. \& Izushi, H. (2003). Hardware gimmick or cultural innovation? Technological, cultural, and social foundations of the Japanese video game industry. Research Policy, 32(3), 423-444.

Badinand-Hubert, N., Bureau, M., Hirsch, E., Masnou, P., Nahum, L., Parain, D. \& Naquet, R. (1998). Epilepsies and video games: Results of a multicentric study. Electroencephalography and Clinical Neurophysiology, 107(6), 422-427.

BBC (2004a). Manhunt game withdrawn by stores. BBC News. [viewed 25 June 2008]. http:// news.bbc.co.uk/2/hi/uk_news/england/leicestershire/3936597.stm

BBC (2004b). Manhunt game sued over murder. BBC News. [viewed 25 June 2008]. http:/ / news.bbc.co.uk/2/hi/uk_news/england/ leicestershire/4124177.stm

BBC (2006). How gaming is all work and no play. BBC News. [viewed 25 June 2008]. http:/ / news.bbc.co.uk/1/hi/technology/4774534.stm

Beck, K., Bergen, M., DeMarco, R., Patel, R., Ocasio, M. \& Servatius, R. (2003). The use of a videogame for assessing sensory-motor and cognitive interference effects in humans. Proceedings of IEEE 29th Annual Bioengineering Conference, 264-265.

Becta (2001). Computer games in education: Findings report. [viewed 25 June 2008]. http: / / partners.becta.org.uk/index.php?section=rh\&rid=13595

Bensley, L. \& Van Eenwyk, J. (2001). Video games and real-life aggression: Review of the literature. Journal of Adolescent Health, 29(4), 244-257.

Blumberg, F. (1998). Developmental differences at play: Children's selective attention and performance in video games. Journal of Applied Developmental Psychology, 19(4), 615-624.

Dixon, G. \& Karboulonis, P. (2000). Development and marketing of interactive entertainment software. Journal of Enterprising Culture, 8(4), 411-436.

EDGE (2002). Wargames. EDGE, 114, 62-68. Bath: Future Publishing,

Egenfeldt-Nielsen, S. (2004). Practical barriers in using educational computer games. On the Horizon, 12(1), 18-21.

Feinstein, A., Mann, S. \& Corsun, D. (2002). Charting the experiential territory. Clarifying definitions and uses of computer simulation, games, and role play. Journal of Management Development, 21(10), 732-744.

Fery, Y-A. \& Ponserre, S. (2001). Enhancing the control of force in putting by video game training. Ergonomics, 44(12), 1025-1037.

Fisher, S. (1994). Identifying video game addiction in children and adolescents. Addictive Behaviors, 19(5), 545-553.

Flowers, P. \& O'Neill, A. (2005). Self-reported distractions of middle school students in listening to music and prose. Journal of Research in Music Education, 53(4), 308-321.

Fries, S. \& Dietz, F. (2007). Learning in the face of temptation: The case of motivational interference. The Journal of Experimental Education, 76(1), 93-112.

Gee, J. (2004). What video games have to teach us about learning and literacy. New York: Palgrave Macmillan.

Greenfield, P., Brannon, C. \& Lohr, D. (1994). Two-dimensional representation of movement through three-dimensional space: The role of video game expertise. Journal of Applied Developmental Psychology, 15, 87-103.

Herz, J. (1997). Joystick Nation. Boston: Little, Brown and Co. 
Hong, J-C. \& Liu, M-C. (2003). A study on thinking strategy between experts and novices of computer games. Computers in Human Behavior, 19, 245-258.

Huang, J. \& Russell, S. (2006). The digital divide and academic achievement. The Electronic Library, 24(2), 160-173.

Huggins, R. \& Izushi, H. (2002). The digital divide and ICT learning in rural communities: Examples of good practice service delivery. Local Economy, 17(2), 111-122.

Jackson, M. (2004). Making visible: Using simulation and game environments across disciplines. On the Horizon, 12(1), 22-25.

Jayakanthan, R. (2002). Application of computer games in the field of education. The Electronic Library, 20(2), 98-102.

Kirsh, S. (2003). The effects of violent video games on adolescents: The overlooked influence of development. Aggression and Violent Behavior, 8, 377-389.

Lamb, T. (2001). Metacognition and motivation - learning to learn. In G. Chambers (Ed), Reflections on motivation. London: CILT.

Lieberman, D. \& Remedios, R. (2007). Do undergraduates' motives for studying change as they progress through their degrees? British Journal of Educational Psychology, 77, 379-395.

Macedonia, M. (2002). Games soldiers play. IEEE Spectrum, 39(3), 32-37.

McFarlane, A., Sparrowhawk, A. \& Heald, Y. (2002). Report on the educational use of games. TEEM. http:/ / www.teem.org.uk/publications/teem_gamesined_full.pdf [viewed 29 January 2008].

Mitchell, A. \& Savill-Smith, C. (2004). The use of computer and video games for learning. A review of the literature. Learning and Skills Development Agency.

http:/ / www.lsda.org.uk/ files/ PDF/ 1529.pdf [viewed 25 June 2008].

Perrone, C., Clark, D. \& Repenning, A. (1996). WebQuest: Substantiating education in edutainment through interactive learning games. Computer Networks and ISDN Systems, 28(7), 1307-1319. Also [verified 26 June 2008] http: / / iw3c2.cs.ust.hk/WWW5/www5conf.inria.fr/fich_html/ papers/P36/Overview.html

Pintrich, P., Brown, D. \& Weinstein, C. (1994). Student motivation, cognition, and learning. Essays in honor of Wilbert J. McKeachie, New Jersey: Lawrence Erlbaum Associates.

Presnky, M. (2001). Digital game-based learning. New York, London: McGraw-Hill Education.

Provenzo, E. (1991). Making sense of Nintendo. Cambridge, MA: Harvard University Press.

Rosas, R., Nussbaum, M., Cumsille, P., Marianov, V., Correa, M., Flores, P., Grau, V., Lagos, F., Lopez, X., Lopez, V., Rodriguez, P. \& Salinas, M. (2003). Beyond Nintendo: Design and assessment of educational video games for first and second grade students. Computers $\mathcal{E}$ Education, 40, 71-94.

Schilling, M. (2003). Technological leapfrogging: Lessons from the U.S. video game console industry. California Management Review, 45(3), 6-32.

Schiefele, U. (1991). Interest, learning, and motivation. Educational Psychologist, 26(3\&4), 299-323.

Stipek, D. (1993). Motivation to learn. From theory to practice (2nd Edition), Massachusetts: Allyn and Bacon.

\section{Appendix}


We are conducting an investigation into whether students' attitudes and playing habits with regard to computer and video games (e.g. PC games, PlayStation and Nintendo) correlate in any way with their exam results. Most of the questions merely require you to tick a box, but your comments will also be appreciated. Filling in this questionnaire will take less than 5 minutes of your time.

Since we will be comparing your gaming attitudes with your examination results as recorded on the University's Academic Records database, we require your specific consent to analyse the information obtained in this research. Naturally, your name will not be mentioned in any document or report. All information will be anonymised, and none will be used for any purpose other than this research.

I hereby give my consent for the information which I submit in this questionnaire to be used for research purposes by the European Business Management School:

Please enter your name and student number before you begin.

First name:

Surname:

Student number:

Question 1: On average, how much time do you spend playing computer and/or video games per day?

$1=$ Never

$2=$ Less than one hour

$3=$ One to two hours

$4=$ Two to three hours

$5=$ Three hours or more

Question 2: Which, if any, of the following machines do you own?

1 to 7 = Playstation2, Xbox, Gamecube, PC, etc.

$8=$ none

Question 3: What types of game do you play?

$1=$ Racing

$2=$ Action

$3=$ Sports

$4=$ Simulation

$5=$ Strategy or role-playing

$6=$ Shooting (first- or third-person)

$7=$ Other - please specify

$8=$ None

Question 4: Roughly how often do you buy new games?

$1=$ Never

$2=$ Very rarely

$3=$ One or two per year

$4=$ One each month

$5=$ Two per month

$6=$ Three or more per month

7 = I don't buy games, but I obtain them from friends/family/rentals

Question 5 (gamers only): Do you stop playing games during or approaching a busy time of study (e.g. lots of assignments, exam periods)?

$1=\mathrm{I}$ do not play games at all during a busy time of study 
$2=$ I reduce the amount of time I spend playing games

$3=$ I continue playing games even during busy times of study

$4=$ I play games even more during busy times of study

Question 6 (gamers only): Do you think that playing games gives you a better chance of improving your performance in assignments and/or exams?

$1=$ Yes, definitely

$2=$ Yes, it is likely

$3=\mathrm{No}$, I don't think it has an effect

$4=$ No, I believe it has the opposite effect

Question 7: Apart from games, what is your attitude towards other forms of entertainment during busy periods of study?

a. TV

b. Music

c. Cinema

d. Social events

For a, b, c, d above:

$1=\mathrm{I}$ do not spend time on this at all during a busy period of study

2 = I reduce the amount of time I spend on this during a busy period of study

$3=$ I continue to spend time on this even during busy periods of study

$4=\mathrm{I}$ spend even more time on this during busy periods of study in order to relax

END

Dr Barry Ip (author for correspondence)

School of Digital Media, Faculty of Applied Design \& Engineering

Swansea Metropolitan University

Mount Pleasant, Swansea SA1 6ED, United Kingdom

Email: barry.ip@smu.ac.uk Web: http:/ / www.smu.ac.uk/

Professor Gabriel Jacobs

Department of Modern Foreign Languages and Literatures

University of Tennessee, USA. Web: http: / / www.utk.edu/

Dr Alan Watkins, School of Business and Economics

Swansea University, UK. Web: http:/ / www.swan.ac.uk/ 